\title{
Design and Development of a Probe-Based Multiplexed Multi- Species Absorption Spectroscopy Sensor for Characterizing Transient Gas-Parameter Distributions in the Intake Systems of I.C. Engines
}

\author{
Gurneesh Jatana $^{1 *}$, Sam Geckler ${ }^{2}$, David Koeberlein ${ }^{2}$, and William Partridge ${ }^{1}$ \\ ${ }^{1}$ Fuels, Engines, and Emissions Research Center, Oak Ridge National Lab, USA \\ ${ }^{2}$ Cummins Inc., USA \\ *Corresponding Author Email: jatanags@ornl.gov
}

\begin{abstract}
A 4-probe multiplexed multi-species absorption spectroscopy sensor system was designed and developed for gas property measurements on the intake side of commercial multicylinder internal-combustion (I.C.) engines; the resulting cycle- and cylinder-resolved concentration, temperature and pressure measurements are applicable for assessing spatial and temporal variations in the recirculated exhaust gas (EGR) distribution at various locations along the intake gas path, which in turn is relevant to assessing cylinder charge uniformity, control strategies, and computational fluid dynamics (CFD) models. The diagnostic is based on absorption spectroscopy and includes an $\mathrm{H}_{2} \mathrm{O}$ absorption system (utilizing a $1.39 \mu \mathrm{m}$ distributed feedback (DFB) diode laser) for measuring gas temperature, pressure, and $\mathrm{H}_{2} \mathrm{O}$ concentration, and a $\mathrm{CO}_{2}$ absorption system (utilizing a $2.7 \mu \mathrm{m}$ DFB diode laser) for measuring $\mathrm{CO}_{2}$ concentration. The various lasers, optical components and detectors were housed in an instrument box, and the $1.39-\mu \mathrm{m}$ and $2.7-\mu \mathrm{m}$ lasers were guided to and from the engine-mounted probes via optical fibers and hollow waveguides, respectively. The $5 \mathrm{kHz}$ measurement bandwidth allows for near-crank angle resolved measurements, with a resolution of 1.2 crank angle degrees at 1000 RPM. The use of compact stainless steel measurement probes enables simultaneous multi-point measurements at various locations on the engine with minimal changes to the base engine hardware; in addition to resolving large-scale spatial variations via simultaneous multi-probe measurements, local spatial gradients can be resolved by translating individual probes. Along with details of various sensor design features and performance, we also demonstrate validation of the spectral parameters of the associated $\mathrm{CO}_{2}$ absorption transitions using both a multi-pass heated cell and the sensor probes. Keywords: Absorption, High-Speed, Temperature, Pressure, Carbon Dioxide, Water Vapor, Spectroscopy
\end{abstract}

\section{Introduction}

Exhaust gas recirculation (EGR) is increasingly being used by engine designers to decrease engine out emissions while maintaining or improving engine efficiency. While, $\mathrm{NO}_{\mathrm{x}}$ control using EGR is now an industry-wide norm for engines, the latest generation of turbocharged and downsized gasoline engines are also starting to make use of EGR to improve knock resistance [1,2]. By effectively increasing a fuel's octane rating [1] and allowing for earlier spark timing, EGR enables improved engine efficiency as well as lower exhaust temperatures, which also reduces turbocharger thermal stress. Additionally, advanced combustion modes such as premixed charge compression ignition (PCCI) [3], reactivity controlled compression ignition (RCCI) [4], and partially premixed combustion (PPC) [5], which are some of the primary engine combustion research areas, require precise knowledge of EGR fraction and temperature of the fresh charge being fed into each cylinder, and the associated charge-parameter fluctuations. Therefore, cycle- and cylinder-resolved measurements of the gas properties (composition and temperature) are of great interest to engine researchers. Such 
measurements require a sensor system with multi-kHz measurement bandwidth, which, traditional measurement devices such as thermocouples and extractive-sampling gas analyzers are not able to provide. Even the Cambustion FastNDIR [6] series of sampling gas analyzers, with their $125 \mathrm{~Hz}$ maximum measurement bandwidth, are not fast enough to resolve engine dynamics that occur on crank-angle timescales [7].

Laser absorption based sensors provide a solution for resolving inter-cycle and intercylinder gas-property transients; specifically, such sensors have been shown to provide multi$\mathrm{kHz}$ bandwidth for measurements in internal combustion engines [7-14] as well as in various other combustion systems including gas turbine engines [15], scramjet combustors [16], and flat flame burners [17]. Furthermore, both $\mathrm{H}_{2} \mathrm{O}$ and $\mathrm{CO}_{2}$ have been used as combustion gas markers in these absorption studies. However, relying solely on $\mathrm{H}_{2} \mathrm{O}$ as an EGR marker could lead to erroneous results due to the use of EGR coolers and fresh charge coolers, both of which work to dehumidify the associated gas streams. As a result, these coolers can remove inlet $\mathrm{H}_{2} \mathrm{O}$ concentration transients, and effectively hide gas dynamics from a downstream $\mathrm{H}_{2} \mathrm{O}$ absorption sensor. On the other hand, $\mathrm{CO}_{2}$ is not removed by these coolers and as such will provide a more accurate characterization of the EGR-air mixing dynamics. In previous work we have described a multi-probe sensor for resolving transient $\mathrm{CO}_{2}$ concentration distributions within an I.C. engine intake system [10], using a single $\mathrm{CO}_{2}$ absorption transition calibrated using the average temperature and pressure of the measurement environment. While that single-line sensor is capable of sufficient accuracy in the relatively isothermal and isobaric conditions throughout most of the intake manifold, it is sensitive to error associated with temperature and pressure variations. For instance, because the amount of light absorbed by a gas-species molecule depends on the gas temperature, pressure, and concentration, the single-line sensor cannot distinguish between high- $\mathrm{CO}_{2}$ concentrations at high temperature and low- $\mathrm{CO}_{2}$ concentrations at low temperature; i.e., hot and cool EGR. Indeed, such hot and cool EGR exist near the intake valve in the form of hot combustion residual backflow from the previous combustion event (which is rebreathed) and the cool fresh EGR-air mixture. Because such advanced measurements are relevant to improved EGR characterization as well as assessing combustion and cylinder-charge fluctuations, we were motivated to develop the associated sensor improvements. The improved multi-species sensor integrates simultaneous high-speed multi-line $\mathrm{H}_{2} \mathrm{O}$ absorption spectroscopy with the original single-line $\mathrm{CO}_{2}$ absorption spectroscopy; temperature, pressure, and $\mathrm{H}_{2} \mathrm{O}$ concentration are determined from the $\mathrm{H}_{2} \mathrm{O}$ measurements and used in the $\mathrm{CO}_{2}$ absorption calculations to determine $\mathrm{CO}_{2}$ concentration at the measured temperature and pressure. The $\mathrm{H}_{2} \mathrm{O}$ absorption based sensor was previously developed and used for line-of-sight gas property (temperature, pressure, and $\mathrm{H}_{2} \mathrm{O}$ concentration) measurements on the intake and exhaust sides of a diesel engine [7,8]. Here we describe the effort to combine and upgrade the two sensors to create a robust probe-based multi-species absorption spectroscopy sensor capable of resolving fast transient $\mathrm{CO}_{2}, \mathrm{H}_{2} \mathrm{O}$, temperature, and pressure distributions via simultaneous measurements from four translatable sensor probes. Validation of the spectral parameters of the selected $\mathrm{CO}_{2}$ absorption transition over a typical intake-manifold temperature range is presented here, along with characterization of the accuracy and uncertainty of the multispecies probe-based sensor.

\section{Absorption Theory}


The theory of absorption spectroscopy is well established [7-13] and therefore, only a brief overview is given here. Laser absorption spectroscopy is a quantitative, species-specific, path-averaged, and minimally-intrusive technique that can be used to measure gas temperature, pressure and species concentration simultaneously in a medium through which the laser radiation is transmitted. For a fixed set of medium properties (pressure, temperature, and absorbing species concentration), maximum absorption occurs when the incident laser radiation frequency matches the resonance frequency (single-photon transition between low and high energy levels) of the absorbing species. In the case of gradients along the absorption path, care must be taken to account for non-linear dependence of the absorption calculation on gas properties; as described in later sections, the probe's compact, folded-path configuration has a small geometric absorption path and mitigates sensitivities to practical intake-manifold gradients. For a monochromatic laser source and a homogeneous gas mixture, this resonant absorption process can be described by the Beer-Lambert relation

$$
I_{L} / I_{o}=\exp \left(-k_{v} * L\right)
$$

where, $I_{o}$ and $I_{L}$ are the incident and transmitted laser irradiance $\left(\mathrm{W} / \mathrm{cm}^{2}\right)$, respectively, $L(\mathrm{~cm})$ is the absorbing medium path length, and $k_{v}\left(\mathrm{~cm}^{-1}\right)$ is the single-transition spectral absorption coefficient at laser light frequency of $v$. The absorption coefficient can be represented by

$$
k_{v}=P * X * S(T) * \phi_{V}
$$

where $P(\mathrm{~atm})$ is the medium pressure, $\phi_{V}(\mathrm{~cm})$ is the Voigt line shape function, $X$ is the absorbing species mole fraction, and $S(T)\left(\mathrm{cm}^{-2} \mathrm{~atm}^{-1}\right)$ is the line-strength of the transition at temperature $T(\mathrm{~K})$. Temperature measurements may be made via the relative height of two or more absorption transition peaks, while the pressure and concentration information is embedded both in the Voigt line shape profile through the collisional broadening half-width $\left(\Delta v_{C}\left(\mathrm{~cm}^{-1}\right)\right.$ in Eq. 3) as well as the partial pressure of the absorbing species. The collisional broadening halfwidth is given by

$$
\Delta v_{C}=2 * P * \sum_{i} X_{i} \gamma_{i}
$$

where, $\gamma_{i}\left(\mathrm{~cm}^{-1} \mathrm{~atm}^{-1}\right)$ is the temperature dependent collisional broadening coefficient. Therefore, all of the target gas properties (i.e. temperature, pressure, and absorbing-species concentration) can be extracted from the absorption signal by recording multiple absorption features. The spectroscopic parameters required for absorption-profile calculations were extracted from the HITRAN 2004 database [18]. The same $\mathrm{H}_{2} \mathrm{O}$ absorption transitions, in the $7201-7206 \mathrm{~cm}^{-1}$ spectral region, used in previous work [7] were also used in this study, as these transitions provide good temperature sensitivity for the gas conditions expected in the intake manifold and the associated spectral parameters have already been verified in literature [19]. For $\mathrm{CO}_{2}$ absorption measurements, the P20 transition centered at $3697.98 \mathrm{~cm}^{-1}$ was used. Spectral

\begin{tabular}{|c|c|c|c|c|c|}
\hline $\begin{array}{c}\text { Line } \\
\text { Number }\end{array}$ & $\begin{array}{l}\text { Transition } \\
\text { Frequency } \\
\quad\left(\mathrm{cm}^{-1}\right)\end{array}$ & $\begin{array}{c}\text { Line Strength } \\
(296 \mathrm{~K}) \\
\left(\mathrm{cm}^{-2} / \mathrm{atm}\right)\end{array}$ & $\begin{array}{c}\text { Rotational Quantum } \\
\text { Numbers } \\
\left(J, K_{a}, K_{c}\right)\end{array}$ & $\begin{array}{c}\text { Vibrational } \\
\text { Quantum Numbers } \\
\left(v_{1}, v_{2}, v_{3}\right)\end{array}$ & $\begin{array}{l}\text { Lower State } \\
\text { Energy } \\
\left(\mathrm{cm}^{-1}\right)\end{array}$ \\
\hline
\end{tabular}
parameters for the selected $\mathrm{H}_{2} \mathrm{O}$ and $\mathrm{CO}_{2}$ transitions are listed in Table 1.

Table 1: Spectroscopic details for the selected $\mathrm{H}_{2} \mathrm{O}$ and $\mathrm{CO}_{2}$ absorption transitions [18]. 


\begin{tabular}{cccccccc}
\hline & & & Upper & Lower & Upper & \multicolumn{2}{l}{ Lower } \\
\hline $\mathrm{H}_{2} \mathrm{O} \_1$ & 7202.26 & $2.52 \mathrm{E}-02$ & $(5,2,4)$ & $(5,2,3)$ & $(1,0,1)$ & $(0,0,0)$ & 446.51 \\
$\mathrm{H}_{2} \mathrm{O} \_2$ & 7202.91 & $1.15 \mathrm{E}-01$ & $(1,0,1)$ & $(2,0,2)$ & $(1,0,1)$ & $(0,0,0)$ & 70.09 \\
$\mathrm{H} 2 \mathrm{O} \_3$ & 7203.66 & $1.49 \mathrm{E}-04$ & $(2,2,0)$ & $(2,2,1)$ & $(1,1,1)$ & $(0,1,0)$ & 1742.31 \\
$\mathrm{H}_{2} \mathrm{O} \_4$ & 7203.89 & $7.38 \mathrm{E}-02$ & $(5,5,1)$ & $(5,5,0)$ & $(1,0,1)$ & $(0,0,0)$ & 742.08 \\
$\mathrm{H}_{2} \mathrm{O} \_5$ & 7204.17 & $7.85 \mathrm{E}-03$ & $(7,4,4)$ & $(7,4,3)$ & $(1,0,1)$ & $(0,0,0)$ & 931.24 \\
$\mathrm{H}_{2} \mathrm{O} \_6$ & 7205.25 & $2.46 \mathrm{E}-01$ & $(1,1,1)$ & $(2,1,2)$ & $(1,0,1)$ & $(0,0,0)$ & 79.50 \\
$\mathrm{CO}_{2}$ 1 & 3697.98 & 1.27 & 0 & 1 & $(1,0,0,1)$ & $(1,0,0,0)$ & 163.87 \\
\hline
\end{tabular}

\section{Experimental System and Methods}

The optical configuration of the sensor system used in this study is illustrated in Fig. 1. The entire optical system is installed in an instrument enclosure which is purged with dry $\mathrm{N}_{2}$ to prevent absorption of the laser light by ambient humidity and $\mathrm{CO}_{2}$. The system has two distributed feedback diode lasers: a 1.39- $\mu \mathrm{m}$ laser (NEL laser with fiber pigtailed output) that probes the $\mathrm{H}_{2} \mathrm{O}$ transitions, and a $2.7-\mu \mathrm{m}$ laser (Nanoplus laser with collimated free space output) that probes the $\mathrm{CO}_{2}$ transition. The output from the fiber-pigtailed $1.39-\mu \mathrm{m}$ laser $\left(\mathrm{H}_{2} \mathrm{O}\right)$ is coupled into a 10:90 fiber splitter (Thorlabs TW1300R2A2), which routes 10\% of the light into a Fabry-Perot spectrum analyzer (1.5 GHz etalon; Thorlabs SA200-12B) to monitor changes in the laser wavelength, and the remaining $90 \%$ of the light into a four-way fiber splitter (Thorlabs FCQ1315-APC). The four-way splitter divides the light into four equal outputs, each of which can be pitched into an individual measurement probe using a single mode fiber (SMF). Because fiber splitters are not available at $2.7 \mu \mathrm{m}$, the collimated free-spaced output from the $2.7-\mu \mathrm{m}$ laser $\left(\mathrm{CO}_{2}\right)$ is split into four beams using a multiplexer unit consisting of a series of free-space mirrors and pellicle beamsplitters [10]. Each of these four beams can be pitched into an individual measurement probe using a hollow-waveguide (HWG). At the probe tip, light from the pitch SMF and HWG traverses two measurement ducts and is reflected back to a catch multimode fiber (MMF) and catch HWG, respectively. This arrangement is described in detail later in this section. The catch MMFs and HWGs deliver the respective laser light from the probes to photodiodes for absorption measurements. The instrument uses 4 sets each of Thorlabs PDA20CS and Vigo PVI-3TE-5 detectors for measuring the 1.39- $\mu \mathrm{m}$ and $2.7-\mu \mathrm{m}$ light signals, respectively to support four independent measurement probes. A solid silicon etalon (41.55-mm long) was applied for offline wavelength calibration of the 2.7- $\mu \mathrm{m}\left(\mathrm{CO}_{2}\right)$ laser. A manifold of critical-flow orifices was used to supply continuous and positive $\mathrm{N}_{2}$ purge to the HWGs, the 2.7$\mu \mathrm{m}$ laser, and the four $\mathrm{H}_{2} \mathrm{O}$ detectors, while, the bulk $\mathrm{N}_{2}$ flow (through an external rotameter) purges the enclosure and remaining optical components.

Figure 1: Schematic of the four-probe multiplexed Two-Color EGR sensor 
The lasers were controlled using a high-performance computer through an integrated temperature and current controller (Thorlabs ITC4001) for the 1.39- $\mu \mathrm{m}$ laser $\left(\mathrm{H}_{2} \mathrm{O}\right)$ and a set of ILX Lightwave temperature (ILX LDT-5910B) and current controllers (ILX LDX-3620) for the 2.7$\mu \mathrm{m}$ laser $\left(\mathrm{CO}_{2}\right)$. Since this study required high measurement bandwidth, the laser temperature was fixed at an optimum value to nominally center the absorption transition(s) in the spectral scanning range, and the laser output wavelength was swept across the desired spectral region by sweeping the current applied across the laser diode. The $1.39-\mu \mathrm{m}$ laser $\left(\mathrm{H}_{2} \mathrm{O}\right)$ current was swept using a shifted-sawtooth modulation function as shown in Fig. 2a (dotted red curve). The shiftedsawtooth function is a normal-sawtooth function with a zero-amplitude rest period at the start of each scan when the laser is effectively turned off; this rest period not only allows the laser to stabilize before each scan starts, but also provides a real-time scan-specific measure of the background infrared radiation (from hot surfaces or gases). Also shown in Fig. 2a is the corresponding recorded transmission curve (thick blue curve) as well as the etalon output (thin green curve) from the $\mathrm{H}_{2} \mathrm{O}$ channel for a single modulation function scan. Data was recorded over 5000 such scans every second to obtain the desired $5 \mathrm{kHz}$ measurement bandwidth. The etalon peak spacing is fixed in wavelength domain by the physical characteristics of the etalon $\left(0.05 \mathrm{~cm}^{-1}\right.$ for the $1.5 \mathrm{GHz}$ etalon used in this study), and the varying time difference between consecutive etalon output peaks in Fig.2a illustrates the nonlinear wavelength response of the laser to linear modulation; therefore, the etalon signal is used to quantify and account for the nonlinear wavelength response of the laser. Figure $2 \mathrm{~b}$ shows the modulation function for the 2.7$\mu \mathrm{m}$ laser $\left(\mathrm{CO}_{2}\right)$, and the corresponding recorded transmission curve (photodiode output). While a normal sawtooth wave was used for $\mathrm{CO}_{2}$ laser modulation, the laser's large threshold current effectively converts its output into a shifted-sawtooth waveform as seen in the recorded photodiode output. The processed absorption data is shown in Fig. $2 \mathrm{c}$ and $2 \mathrm{~d}$ for the $\mathrm{H}_{2} \mathrm{O}$ and $\mathrm{CO}_{2}$ channels, respectively. The data processing methodology is described in detail in prior work [7] and only a brief overview is given here. The raw time-domain transmission data $\left(I_{L}\right.$ in Eq. 1) is converted into linear wavelength domain using the etalon output for comparison with the theoretical absorption model described in the previous section. This comparison is performed using a Levenberg-Marquardt [20] based least-square fitting routine implemented in MATLAB. This routine takes the raw time-domain transmission data, the etalon output, and the path length as inputs to determine the zero-absorption transmission profile ( $I_{o}$ in Eq. 1$)$, and the desired gas properties as outputs. Typically, direct absorption measurements require the zero-absorption transmission profile (of the optical arrangement being used for the measurements) to either be measured in a non-absorbing medium prior to the actual measurements or be calculated from the measured absorption spectra using the zero-absorption transition wings; however, both these conditions impose significant limitations on the accuracy and measurement bandwidth of the direct absorption measurements. The novel iterative scheme used in this study and described in prior work [7], on the other hand, computes the zero-absorption profile from the measured absorption spectra without requiring the presence of zero-absorption wings; therefore, allowing for accurate high-bandwidth measurements even under conditions of transient broadband attenuation (which can be caused by factors such as window fouling and beam steering) of the laser light. As previously mentioned, scanning of multiple $\mathrm{H}_{2} \mathrm{O}$ absorption transitions allows for measurement of multiple gas properties ( $\mathrm{T}, \mathrm{P}, \mathrm{H}_{2} \mathrm{O}$ concentration), but the $\mathrm{CO}_{2}$ absorption data could only provide information about a single gas property as only one $\mathrm{CO}_{2}$ transition is measured. Therefore, the temperature and pressure measurements obtained from $\mathrm{H}_{2} \mathrm{O}$ absorption were used to process the simultaneously measured $\mathrm{CO}_{2}$ absorption data to determine $\mathrm{CO}_{2}$ 
concentration values. Finally, due to the optical arrangement of the probe, considerable etaloning noise was observed in the absorption signals as seen in Fig. 2c. This etaloning noise, which was a result of self-interference of light due to reflections in the probe optics, introduced errors in the measurements by distorting the absorption curve shape. The exact impact of the etaloning noise is discussed in subsequent sections.

Figure 2: Raw data from a typical $\mathrm{H}_{2} \mathrm{O}$ (a) and $\mathrm{CO}_{2}$ (b) signal channel using the shifted saw-tooth modulation. Also shown are the respective processed absorption signals for $\mathrm{H}_{2} \mathrm{O}$ (c) and $\mathrm{CO}_{2}$ (d) absorption. (Measurements performed in $300 \mathrm{~K}$ humid mixture of $99 \%\left[\mathrm{~N}_{2}\right]$ and $1 \%\left[\mathrm{CO}_{2}\right]$ ).

\section{EGR Probe Details}

The measurement probe used in this study, and illustrated in Fig. 3a, is an upgraded version of the probe described in prior work $[9,10]$. This compact probe comprises of a 9.525mm (3/8-inch) outer diameter (OD) stainless steel (SS) tube which houses the measurement-cell optics as well as the optical media to guide the light, i.e. the pitch and catch optical fibers and HWGs. An SS collet fixes the fibers and the HWGs in the probe in an optically optimum arrangement as shown in Fig. 3b. The SMF (Thorlabs 1310BHP) has $10-\mu \mathrm{m}$ core diameter and $0.25-\mathrm{mm}$ OD; therefore, to bolster its structural integrity and strength, the SMF is epoxied in an SS sleeve (0.27-mm ID and 0.8-mm OD). However, the optimal optical arrangement introduces a physical interference of the SMF sleeve with the catch HWG and, as also shown in Fig. 3b, the SMF sleeve is chamfered on one side to solve this issue. To ensure high catch efficiency, the selected MMF (Thorlabs FT800EMT) has a large core diameter and numerical aperture of 0.8 $\mathrm{mm}$ and 0.39, respectively. A 0.5-mm ID HWG (Polymicro HWEA500850) is used to pitch the 2.7- $\mu \mathrm{m}$ light into the probe and a 1-mm ID HWG (Polymicro HWEA10001600) to catch the 2.7$\mu \mathrm{m}$ light transmitted through the probe measurement cells. The measurement cell optics couple light between pitch and catch media, and also define the two measurement ducts where the light beams are exposed to the measurement flow for absorption; these optics consist of a 5-mm diameter sapphire window to isolate probe internals from the measurement flow, a 6-mm diameter sapphire half-ball lens, and a gold coated mirror. Light interacts with the gas species in the probe's two measurement ducts formed by the space between the window \& lens and the lens $\&$ mirror. After exiting the pitch media, the light traverses these measurement ducts twice to reach the catch media resulting in an absorption path length of $12 \mathrm{~mm}$ in just $8 \mathrm{~mm}$ of physical footprint. For mounting the probes on the engine, the only change required on the base engine hardware is the installation of a 3/8-inch Swagelok connector; a non-swaging graphite ferrule can then be used to allow probe translation for spatial mapping studies with $8 \mathrm{~mm}$ spatial resolution.

Figure 3: a) A sectioned view of the optical arrangement in the measurement tip of the Multi-Species EGR Probe; b) illustration showing the optical arrangement in the Multi-Species probe collet.

\section{Sensor Validation}

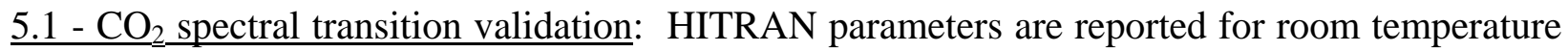
conditions and may not be valid at elevated temperatures; furthermore, even for room 
temperature measurements, the HITRAN parameters have a reported uncertainty of up to $5 \%$. Therefore, measurements were performed in a heated gas cell to validate the spectral parameters for the selected $\mathrm{CO}_{2}$ absorption transition. Gas temperature in the intake manifold is not expected to be higher than $500 \mathrm{~K}$ due to the presence of the charge-air and EGR coolers; therefore, the validation was performed for a gas temperature sweep from $300 \mathrm{~K}$ to $500 \mathrm{~K}$ in $50 \mathrm{~K}$ steps. As illustrated in Fig. 4a, the 400-mm long high-temperature gas cell features recessed sapphire windows for a net line-of-sight absorption path length of $120 \mathrm{~mm}$ in the middle of the cell. The recessed windows help in reducing any temperature gradients along the absorption path length. Figure $4 \mathrm{~b}$ shows the assembled calibration setup used for this study. The cell was instrumented with four thermocouples (Omega KMQSS-125-E6) to monitor temperature uniformity across the absorption path length and all the thermocouples read within $5 \mathrm{~K}$ of each other at all validation temperatures; indicating uniform temperature across the absorption path. For analysis, the measurement cell was filled with a dry mixture of $1 \% \mathrm{CO}_{2}$ and $99 \% \mathrm{~N}_{2}$, and the entire laser path outside of the measurement region (outside of the $120 \mathrm{~mm}$ absorption path indicated in Fig.5a) was purged with $\mathrm{N}_{2}$ to prevent interference by atmospheric $\mathrm{CO}_{2}$. As shown in Figure 5, very good agreement was achieved between the experimentally measured spectra and the theoretical absorption fits at all temperatures. Figure 6 shows average (of 1 second of data at $5 \mathrm{kHz}$ ) measured $\mathrm{CO}_{2}$ concentrations for three independent temperature sweeps, and illustrates the similarly good agreement between measurements and reference; specifically, the measurements are within $2 \%$ of the reference concentration, and the single-shot $(5 \mathrm{kHz})$ standard deviation was only $\sim 0.5 \%$ (cf. error bars on the $350 \mathrm{~K}$ data). Significantly, these mean and standard deviation values were calculated from the cumulative data of the three different temperature sweeps, which were all conducted on different days. The excellent agreement between the experimental and theoretical absorption profiles in Fig. 5, and the measured and reference values in Fig. 6 validate the spectroscopic parameters used in the calculations over the desired gas property range.

Figure 4: a) Disassembled gas cell showing the offset windows designed to provide a near uniform temperature across a reduced path length; b) setup for $\mathrm{CO}_{2}$ spectral parameter validation at elevated temperatures

Figure 5: Sample experimental $\mathrm{CO}_{2}$ absorption curves recorded at gas temperatures of $300 \mathrm{~K}$ (circles), $400 \mathrm{~K}$ (squares), and 500K (triangles) along with the respective theoretical model fits (red lines). These non-averaged curves capture absorption across a path-length of $120 \mathrm{~mm}$ in a $1 \mathrm{~atm}$. medium of $1 \% \mathrm{CO}_{2}$. (5000 such curves are recorded every second).

Figure 6: Measured $\mathrm{CO}_{2}$ concentrations at various temperatures from 300 to $500 \mathrm{~K}$ for three independent temperature sweeps. All measurements are within $2 \%$ of the reference concentration with a single shot standard deviation of up to $0.5 \%$.

5.2 - Multi-Species EGR Probe performance validation: Measurements were performed in a laboratory flowing-gas cell to validate the probe-based sensor performance. As shown in Fig. 7, the validation setup consists of a gas cell that can simultaneously accommodate four EGR probes, five thermocouples, and a pressure sensor. The reference gas was synthesized by mixing desired proportions of bottled dry $\mathrm{N}_{2}$ and $\mathrm{CO}_{2}$ standard using a 10-point gas divider (Stec SGD710C). This dry gas mixture was then humidified by passing it through an $\mathrm{H}_{2} \mathrm{O}$ bubbler- 
condenser assembly, and subsequently heated to the desired temperature before being fed into the gas cell for absorption measurements. Validation was performed using a $0.2-2 \%$ dry-mixture $\mathrm{CO}_{2}$ concentration range at gas temperatures of $300 \mathrm{~K}, 430 \mathrm{~K}$, and $505 \mathrm{~K}$, and constant 1-atm gas cell pressure. In initial evaluations, the presence of etaloning was observed in both the $\mathrm{H}_{2} \mathrm{O}$ and $\mathrm{CO}_{2}$ absorption signals; moreover, the etaloning patterns changed with shaking (movement) of the probes and/or the fibers (hereby referring to both the optical fibers and HWGs). As mentioned earlier, etalons distort the absorption curve shape and introduce measurement errors; therefore, multiple tests were performed to capture the impact of the changing etalon profiles on measurement accuracy. After achieving the desired steady state temperature, the dry-gas $\mathrm{CO}_{2}$ concentration was swept from $0.2-2 \%$ without disturbing the probes or the fibers to ensure that the etaloning did not contribute to the measured standard deviation; i.e., measurements were performed at a fixed or stable etalon spectral pattern. After a $\mathrm{CO}_{2}$ sweep, the fibers were shaken to induce a different etaloning mode, and the $\mathrm{CO}_{2}$ concentration sweep was repeated after the fibers came to a rest and a new fixed etalon mode was established. In all, ten such sweeps were performed to establish statistics for characterizing the effect of vibration-induced etalon changes on the sensor measurements. Tables 2, 3, and 4 show the sensor validation results at the three gas temperatures. The standard deviation recorded within a sweep (i.e., at a fixed etalon mode and no vibrations) primarily originated from the electronic noise in various sensor components and therefore, represented the 'intrinsic' uncertainty as listed in the tables; on the other hand, 'etaloninduced' standard deviation (as listed in the tables) is the standard deviation of the mean gas properties recorded across the ten measurement sweeps (or ten different etalon modes) and originates from the absorption-curve distortion caused by the changing etalon profiles. In all the cases, 'etalon-induced' standard deviation was significantly higher than the corresponding 'intrinsic' standard deviation; therefore, this illustrates the severe uncertainty penalty imposed by the presence of etalons and the sensor performance benefits that would be achieved by eliminating all etalons form the signal. For all the recorded cases, mean values of the measured gas properties were within $10 \%$ of the reference values. As shown in Fig. 8, the average measured $\mathrm{CO}_{2}$ concentrations matched very well with the standard concentrations supplied to the gas cell at all three temperatures; the measurements were within $10 \%$ of the reference values for concentrations above $0.4 \% \mathrm{CO}_{2}$. The 'inter-probe' standard deviation is the variation between the mean measurements of the four probes and was observed to be comparable to the measured intrinsic standard deviation for room temperature measurements. Furthermore, the 'inter-probe' standard deviation was only defined for room temperature measurements as at high temperatures each probe will be exposed to a different gas temperature due to cooling of the reference gas as it flows along the uninsulated gas cell; additionally, with the inter-probe variability established at ambient temperature, data from a single probe was sufficient to validate sensor performance at high temperatures. The low inter-probe deviation indicates that large-scale gradients (e.g., across an intake manifold, and beyond the range of single-probe translation) may be faithfully resolved by comparing measurements from separate probes arrayed across the gradient. Overall, based on the recorded $2 \sigma$ standard deviations, the detection limit for both the $\mathrm{H}_{2} \mathrm{O}$ and $\mathrm{CO}_{2}$ concentration measurements can be defined as $0.4 \%$ (ca. 3\% EGR for around $13.3 \%$ exhaust $\mathrm{CO}_{2}$ levels). Typical EGR values are 5\% for gasoline and $10 \%$ for diesel, although much higher values are possible. The measured $\mathrm{CO}_{2}$ detection limit is, therefore, appropriate for engine applications. 
Table 2: Sensor validation data at $300 \mathrm{~K}$ gas temperature and ambient pressure

\begin{tabular}{|c|c|c|c|c|}
\hline \multirow{2}{*}{ Sensor Meas. } & \multirow{2}{*}{ Mean } & \multicolumn{3}{|c|}{ Std. Dev. } \\
\cline { 3 - 5 } & & Intrinsic & $\begin{array}{c}\text { Etalon } \\
\text { Induced }\end{array}$ & Inter Probe \\
\hline Temperature (K) & 300 & 6 & 18 & 4 \\
\hline Pressure (atm) & 1 & 0.08 & 0.12 & 0.08 \\
\hline$\% \mathrm{H}_{2} \mathrm{O}$ & 2.1 & 0.05 & 0.25 & 0.07 \\
\hline$\% \mathrm{CO}_{2}$ & - & 0.04 & 0.17 & 0.04 \\
\hline
\end{tabular}

Table 3: Sensor validation data at $430 \mathrm{~K}$ gas temperature and ambient pressure

\begin{tabular}{|c|c|c|c|}
\hline \multirow{2}{*}{ Sensor Meas. } & \multirow{2}{*}{ Mean } & \multicolumn{2}{|c|}{ Std. Dev. } \\
\cline { 3 - 4 } & & Intrinsic & $\begin{array}{c}\text { Etalon } \\
\text { Induced }\end{array}$ \\
\hline Temperature (K) & 401 & 12 & 29 \\
\hline Pressure (atm) & 1.1 & 0.08 & 0.14 \\
\hline$\% \mathrm{H}_{2} \mathrm{O}$ & 2.2 & 0.06 & 0.22 \\
\hline$\% \mathrm{CO}_{2}$ & - & 0.07 & 0.18 \\
\hline
\end{tabular}

Table 4: Sensor validation data at $505 \mathrm{~K}$ gas temperature and ambient pressure

\begin{tabular}{|c|c|c|c|}
\hline \multirow{2}{*}{ Sensor Meas. } & \multirow{2}{*}{ Mean } & \multicolumn{2}{|c|}{ Std. Dev. } \\
\cline { 3 - 4 } & & Intrinsic & $\begin{array}{c}\text { Etalon } \\
\text { Induced }\end{array}$ \\
\hline Temperature $(\mathrm{K})$ & 485 & 22 & 33 \\
\hline Pressure $(\mathrm{atm})$ & 1.2 & 0.08 & 0.09 \\
\hline$\% \mathrm{H}_{2} \mathrm{O}$ & 2.2 & 0.06 & 0.2 \\
\hline$\% \mathrm{CO}_{2}$ & - & 0.12 & 0.18 \\
\hline
\end{tabular}

Figure 7: Laboratory arrangement for sensor validation

Figure 8: $\mathrm{CO}_{2}$ concentration sweep at different gas temperatures.

\section{Engine-Application Demonstration}

Figure 9 shows an application of the Multi-Species EGR Probe diagnostic to measure $\mathrm{CO}_{2}$ and $\mathrm{H}_{2} \mathrm{O}$ transients in the intake system of an operating multi-cylinder engine; these are at the instrument native temporal resolution of $5 \mathrm{kHz}$, and without any point or cycle averaging. The measurements show EGR transients over a wide range of timescales (high and lower frequency), and synchronous $\mathrm{CO}_{2}$ and $\mathrm{H}_{2} \mathrm{O}$ variations. Similar data can be acquired at various probe positions/locations for spatiotemporal engine-system mapping. While the main intent herein is to describe the instrument, Figure 9 demonstrates an engine application of the multi-species probe. Other engine applications have been published using earlier versions of the EGR Probe $[9,10]$. We intend a separate publication to focus on engine applications of the multi-species probe. 
Figure 9: Measurement of high- and low-frequency $\mathrm{CO}_{2}$ and $\mathrm{H}_{2} \mathrm{O}$ transients in the intake system of a multi-cylinder engine during operation with EGR.

\section{Conclusions}

A four-probe-multiplexed Multi-Species EGR Probe diagnostic was designed and developed to perform high-speed $(5 \mathrm{kHz})$ measurements of gas temperature, pressure, and $\mathrm{H}_{2} \mathrm{O}$ and $\mathrm{CO}_{2}$ concentration in the intake manifold of IC engines. The diagnostic is implemented via probebased measurements which allow for spatial mapping of property distributions via single-probe translation, and on-engine measurements with minimal modifications to the base engine hardware; furthermore, 4 probes can be utilized simultaneously to map larger-scale property gradients via multi-location measurements. The spectral parameters of the chosen $\mathrm{CO}_{2}$ absorption transition were verified using a high-temperature gas cell for the temperature conditions expected in the intake manifold. The $\mathrm{CO}_{2}$ concentration measured by the spectral model was within $2 \%$ of the reference concentration and the single-shot standard deviation was $\sim 0.5 \%$. Measurement accuracy and standard deviation of the multi-species probes were also characterized in a gas cell. While the single shot standard deviation was observed to be within $5 \%$, the presence of etalons induced by the probe had a negative impact on the sensor accuracy; the sensor measurements were nevertheless within $10 \%$ of the reference values. Future iterations of the probe optics will be designed to reduce or eliminate the etalons to further improve the sensor accuracy and uncertainty. Replacing the window and the half-ball lens with a customdesigned rod lens will eliminate two parallel surfaces (of the window) and result in lower etaloning levels. AR coating of the fiber tips would also be employed to further reduce backreflections. In application, measurements performed using the Multi-Species EGR Probe diagnostic will provide insights into the spatio-temporal variations of the gas properties, which are critical for assessing hardware configurations, calibrating and validating CFD models, and developing control strategies to advance research in higher-efficiency engine systems.

\section{Acknowledgements}

This research was funded by the US DOE Vehicle Technologies Office via a Cooperative Research and Development Agreement between ORNL and Cummins Inc., and Cummins Inc. via subcontract on their DOE-supported Cummins-Peterbilt SuperTruck project. The authors would like to thank DOE Program Managers Gurpreet Singh, Ken Howden and Leo Breton.

This manuscript has been authored by UT-Battelle, LLC under Contract No. DE-AC0500OR22725 with the U.S. Department of Energy. The United States Government retains and the publisher, by accepting the article for publication, acknowledges that the United States Government retains a non-exclusive, paid-up, irrevocable, world-wide license to publish or reproduce the published form of this manuscript, or allow others to do so, for United States Government purposes. The Department of Energy will provide public access to these results of federally sponsored research in accordance with the DOE Public Access Plan (http://energy.gov/downloads/doe-public-access-plan).

\section{References}


[1] Alger T, Mangold B, Roberts C, Gingrich J. "The Interaction of Fuel Anti-Knock Index and Cooled EGR on Engine Performance and Efficiency," SAE Int. J. Engines. 2012; 5(3), doi:10.4271/2012-01-1149

[2] Alger T, Chauvet T, Dimitrova Z. "Synergies between High EGR Operation and GDI Systems," SAE Int. J. Engines. 2008; 1(1), doi:10.4271/2008-01-0134.

[3] W. Hardy and R. Reitz, "A study of the effects of high EGR, high equivalence ratio, and mixing time on emissions levels in a heavy-duty diesel engine for PCCI combustion," SAE Technical Paper 2006-01-0026 (2006).

[4] D. Splitter, R. Hanson, S. Kokjohn, and R. Reitz, "Reactivity controlled compression ignition (RCCI) heavy-duty engine operation at mid-and high-loads with conventional and alternative fuels," SAE Technical Paper 2011-01-0363 (2011).

[5] L. Hildingsson, G. Kalghatgi, N. Tait, B. Johansson, and A. Harrison, "Fuel octane effects in the partially premixed combustion regime in compression ignition engines," SAE Technical Paper 2009-1-2648 (2009).

[6] M. Peckham, A. Finch, and B. Campbell, "Analysis of Transient HC, CO, NOx and CO2 Emissions from a GDI Engine using Fast Response Gas Analyzers," SAE Technical Paper 2011-01-1227 (2011).

[7] G.S. Jatana, S.V. Naik, G.M. Shaver, and R.P. Lucht, "High-speed diode laser measurements of temperature and water vapor concentration in the intake manifold of a diesel engine," International Journal of Engine Research 15(7), 773 (2014).

[8] G.S. Jatana, M. Magee, D. Fain, S.V. Naik, G.M. Shaver, and R.P. Lucht, "Simultaneous high-speed gas property measurements at the EGR cooler exit and at the turbocharger inlet of a multi-cylinder diesel engine using diode-laser-absorption-spectroscopy," Applied Optics 54 (2015) 1220 - 1231.

[9] J. Yoo, V. Prikhodko, J.E. Parks, A. Perfetto, S. Geckler, W.P. Partridge (2015). "Fast Spatially-Resolved EGR Distribution Measurements in an Internal Combustion Engine using Absorption Spectroscopy,” Applied Spectroscopy 69, No. 9, 1047-1058.

[10] J. Yoo, V. Prikhodko, J.E. Parks, A. Perfetto, S. Geckler, W.P. Partridge (2016). "High-speed multiplexed spatiotemporally resolved measurements of EGR dynamics in a multi-cylinder engine using laser absorption spectroscopy," Applied Spectroscopy 70, No. 4, 572-584.

[11] N. Kawahara, E. Tomita, A. Ohtsuki, and Y. Aoyagi, "Cycle-resolved residual gas concentration measurement inside a heavy-duty diesel engine using infrared laser absorption," Proceedings of the Combustion Institute 33(2), 2903 (2011).

[12] G. B. Rieker, H. Li, X. Liu, J. T. C Liu, J. B. Jeffries, R. K. Hanson, M. G. Allen, S. D. Wehe, P. A. Mulhall, H. S. Kindle, A. Kakuho, K. R. Sholes, T. Matsuura, and S. Takatani, "Rapid measurements of temperature and $\mathrm{H} 2 \mathrm{O}$ concentration in IC engines with a spark plugmounted diode laser sensor," Proceedings of the Combustion Institute 31(2), 3041 (2007).

[13] O. Witzel, A. Klein, C. Meffert, and S. Wagner, "VCSEL-based, high-speed, in situ TDLAS for in-cylinder water vapor measurements in IC engines," Opt Express 21(7), 19951 (2013).

[14] L. Kranendonk, X. An, A.W. Caswell, R. E. Herold, S. T. Sanders, R. Huber, J. G. Fujimoto, Y. Okura, and Y. Urato, "High speed engine gas thermometry by Fourier-domain modelocked laser absorption spectroscopy," Optics Express 15(23), 15115 (2007).

[15] L. Ma, X. Li, S. T. Sanders, A. W. Caswell, S. Roy, D. H. Plemmons, and J. R. Gord, "50$\mathrm{kHz}$-rate 2D imaging of temperature and $\mathrm{H} 2 \mathrm{O}$ concentration at the exhaust plane of a J85 engine using hyperspectral tomography," Optics Express 21(1), 1152 (2013). 
[16] G. Rieker, J. Jeffries, R. Hanson, T. Mathur, M. Gruber, and C. Carter, "Diode laser-based detection of combustor instabilities with application to a scramjet engine," Proceedings of the Combustion Institute 32(1), 831 (2009).

[17] R. M. Mihalcea, D. S. Baer, and R. K. Hanson, "Advanced diode laser absorption sensor for in situ combustion measurements of $\mathrm{CO} 2, \mathrm{H} 2 \mathrm{O}$, and gas temperature," Symposium (International) on Combustion 27(1), 95 (1998).

[18] L. S. Rothman, D. Jacquemart, A. Barbe, D. C. Benner, M. Birk, L. R. Brown, M. R. Carleer, C. Chackerian, Jr., K. Chance, L. H. Coudert, V. Dana, V. M. Devi, J. M. Flaud, R. R. Gamache, A. Goldman, J. M. Hartmann, K. W. Jucks, A. G. Maki, J. Y. Mandin, S. T. Massie, J. Orphal, A. Perrin, C. P. Rinsland, M. A. H. Smith, J. Tennyson, R. N. Tolchenov, R. A. Toth, J. V. Auwera, P. Varanasi, and G. Wagner, "The HITRAN 2004 molecular spectroscopic database," J. Quant. Spectrosc. Radiat. Transf. 96(2), 139 (2005).

[19] X. Liu, X. Zhou,, J. B. Jeffries, and R. K. Hanson, "Experimental Study of H2O spectroscopic Parameters in the Near-IR," 43rd AIAA Aerospace Sciences Meeting and Exhibit, 829 (2005).

[20] Seber GAF, and Wild CJ. Nonlinear Regression. Hoboken, NJ: Wiley-Interscience, 2003.

\section{Biographies}

Dr. Gurneesh Singh Jatana completed his PhD from Purdue University in 2014 and is currently working as a post-doctoral research scholar at Oak Ridge National Lab. His research focuses on development of absorption-spectroscopy-based gas property sensors and their application for measurements on production spec. multi-cylinder I.C. engines to provide highspeed data for CFD model validation/tuning and control model development. He is also working on understanding the cyclic variability of combustion in SI engines under high-dilution operation to improve engine stability at the dilution limit.

Mr. Sam Geckler earned Bachelor and Masters of Mechanical Engineering from Purdue University in 1992 and 1994 respectively. He joined powertrain consulting group FEV in 1994 and held engine performance development roles in alternative fuels programs, diesel combustion system design and after-treatment integration. Since 2002, he has been with Cummins Inc. At Cummins, he was the engine performance leader for the 2007 RAM truck program launching the first Heavy Duty truck using NOx adsorber technology, and more recently he was the program leader for the Cummins ETHOS program demonstrating high efficiency spark ignited engine concepts based upon low carbon fuels.

Mr. David Koeberlein joined Cummins in 1980, and received his Bachelor degree in Mechanical Engineering from University of Louisville, Speed Scientific School in 1982. He is currently Director of Advanced Engineering Design. His work has encompassed structural analysis, experimentation methods, design and development of engine and vehicle components, and was instrumental to the successful 1989 Cummins powered Dodge Ram pickup launch, and development of an automated oil replenishment system, and a family of V6 and V8 light duty diesel engines. He led the successful Cummins-Peterbilt Supertruck team to achieving $86 \%$ freight efficiency improvement in a Class 8 on-highway truck. 
Dr. W. P. Partridge completed his PhD work at Purdue University in 1995, and is currently Distinguished Research Staff at Oak Ridge National Laboratory (ORNL). His research focuses on developing and applying robust, practical and field-deployable diagnostics to advance transportation technologies, with specific emphasis on combustion, catalysis, and engine systems; these have contributed to several significant Cummins advances including the 2015 5L V8 (Nissan Titan), the SuperTruck and 2007 6.7L ISB (Dodge Ram). He was recognized as ORNL's 2008 Distinguished Engineer, and received the 2010 Outstanding Mentor Award from the US DOE Office of Science for his work with students and post-graduates. 
All figures are "ONLINE ONLY" Color.

\begin{tabular}{|c|l|}
\hline Figure \# & \multicolumn{1}{|c|}{ Caption } \\
\hline 1 & Schematic of the four-probe multiplexed Two-Color EGR sensor. \\
\hline 2 & $\begin{array}{l}\text { Raw data from a typical } \mathrm{H}_{2} \mathrm{O}(\mathrm{a}) \text { and } \mathrm{CO}_{2} \text { (b) signal channel using the shifted saw-tooth modulation. } \\
\text { Also shown are the respective processed absorption signals for } \mathrm{H}_{2} \mathrm{O}(\mathrm{c}) \text { and } \mathrm{CO}_{2} \text { (d) absorption. } \\
\text { (Measurements performed in } 300 \mathrm{~K} \text { humid mixture of } 99 \%\left[\mathrm{~N}_{2}\right] \text { and } 1 \%\left[\mathrm{CO}_{2}\right] \text { ). }\end{array}$ \\
\hline 3 & $\begin{array}{l}\text { a) Illustration showing the Multi-Species EGR Probe details and arrangement; } \text { b) illustration showing } \\
\text { the optical arrangement in the Multi-Species probe collet. }\end{array}$ \\
\hline 4 & $\begin{array}{l}\text { a) Disassembled gas cell showing the offset windows designed to provide a near uniform } \\
\text { temperature across a reduced path length; b) setup for } \mathrm{CO}_{2} \text { spectral parameter validation at } \\
\text { elevated temperatures. }\end{array}$ \\
\hline 5 & $\begin{array}{l}\text { Sample experimental } \mathrm{CO}_{2} \text { absorption curves recorded at gas temperatures of 300K (circles), } \\
400 \mathrm{~K} \text { (squares), and } 500 \mathrm{~K} \text { (triangles) along with the respective theoretical model fits (red } \\
\text { lines). These non-averaged curves capture absorption across a path-length of 120mm in a } 1 \\
\text { atm. medium of } 1 \% \mathrm{CO}_{2} \text {. (5000 such curves are recorded every second). }\end{array}$ \\
\hline 6 & $\begin{array}{l}\text { Measured } \mathrm{CO}_{2} \text { concentrations at various temperatures from 300 to 500K for three independent } \\
\text { temperature sweeps. All measurements are within } 2 \% \text { of the reference concentration with a single shot } \\
\text { standard deviation of up to 0.5\%. }\end{array}$ \\
\hline 7 & Laboratory arrangement for sensor validation. \\
\hline 8 & $\begin{array}{l}\text { CO }{ }_{2} \text { concentration sweep at different gas temperatures. } \\
\text { Measurement of high- and low-frequency CO } \mathrm{C}_{2} \text { and } \mathrm{H}_{2} \mathrm{O} \text { transients in the intake system of a multi- } \\
\text { cylinder engine during operation with EGR. }\end{array}$ \\
\hline
\end{tabular}




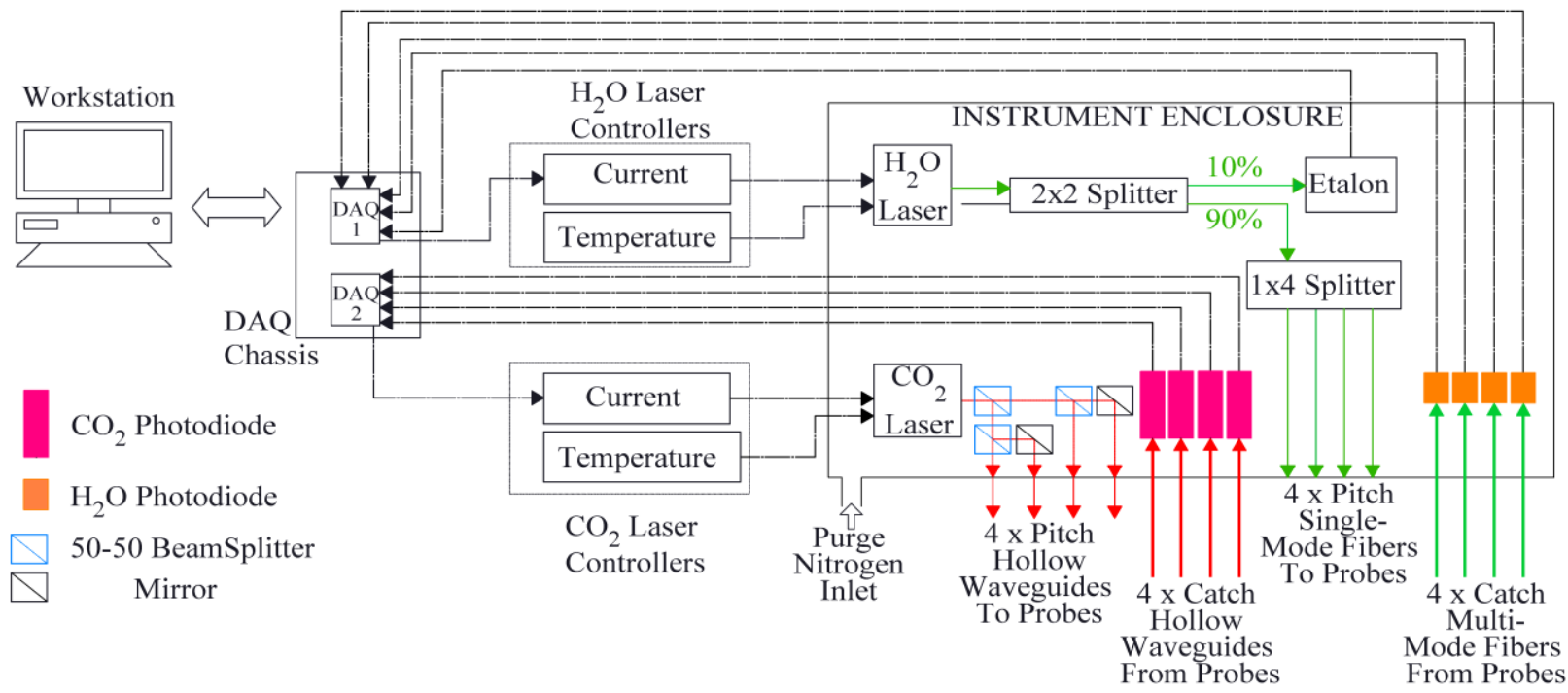



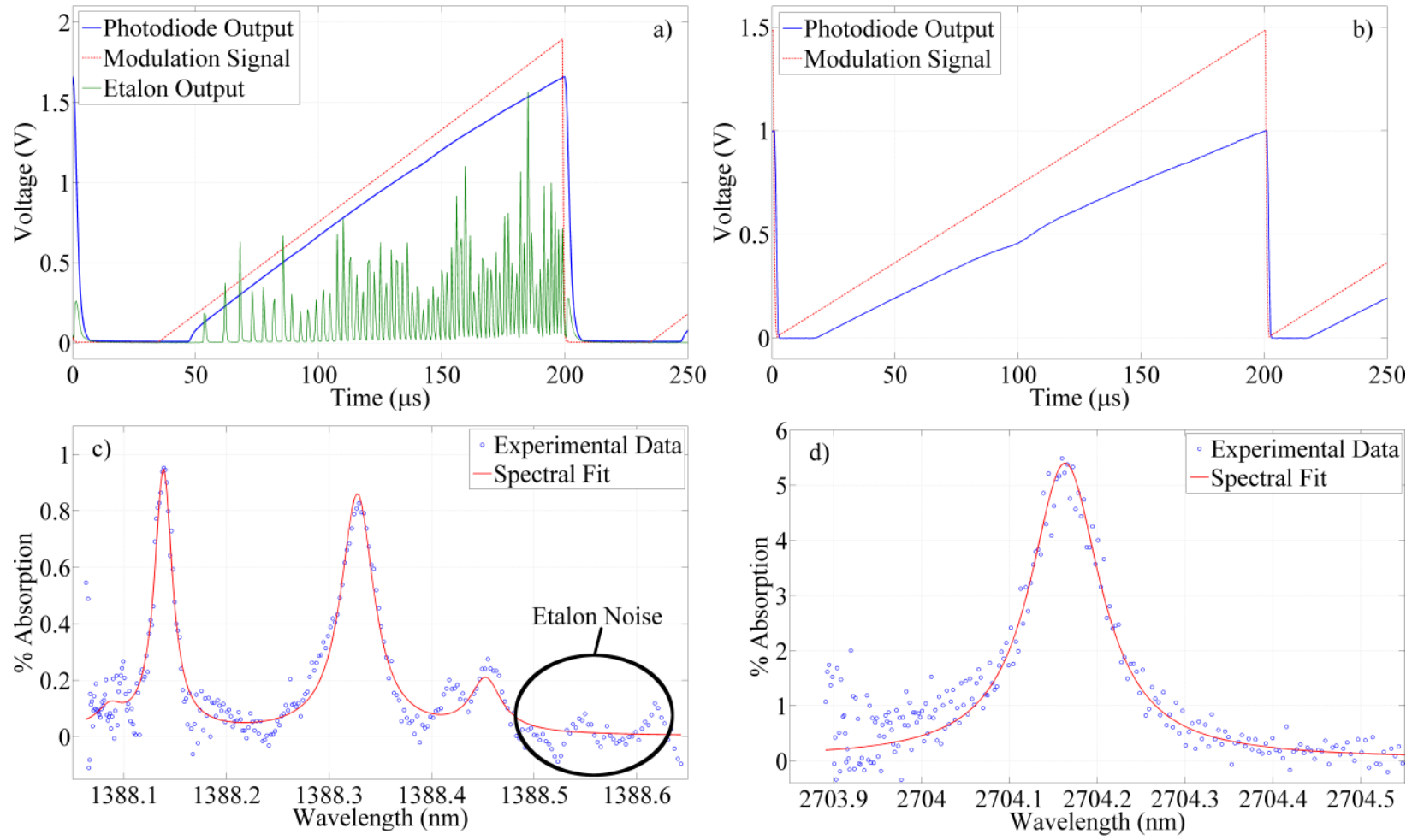

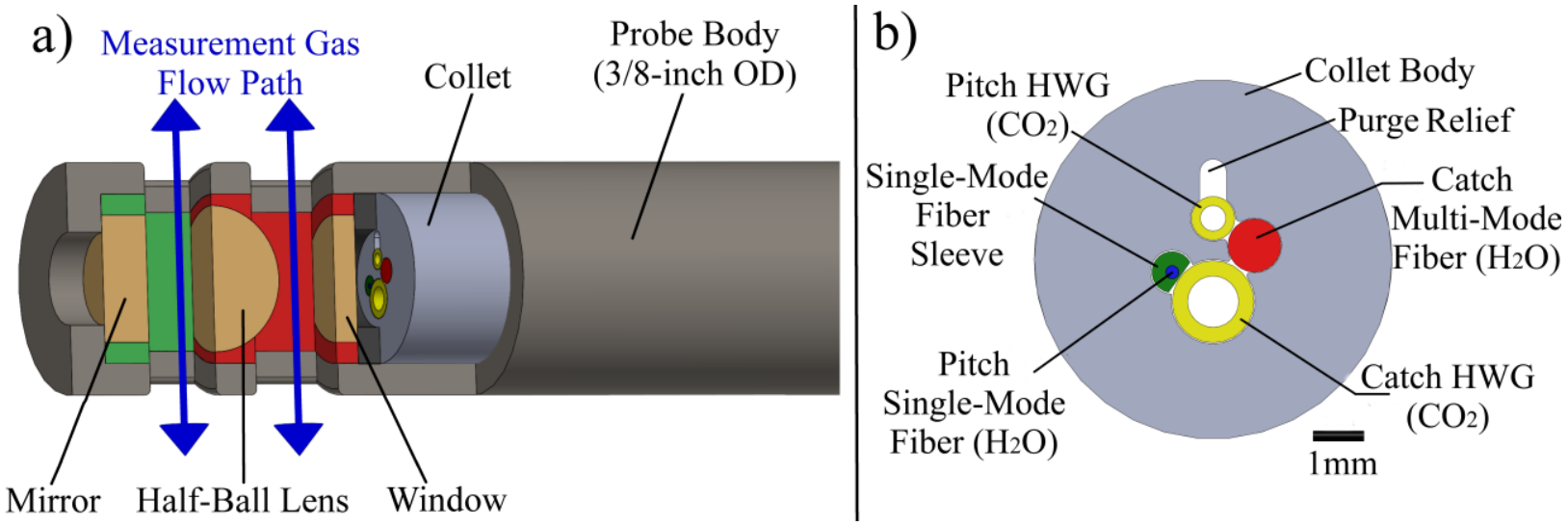


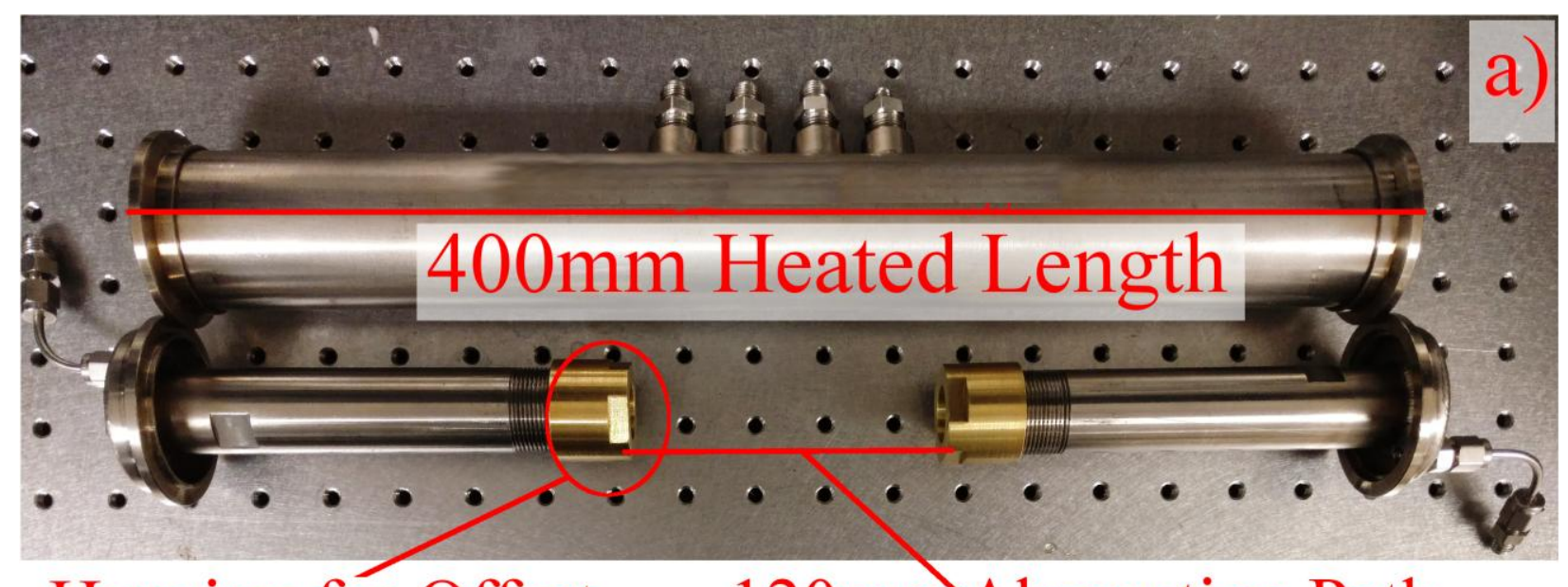

Housing for Offset $120 \mathrm{~mm}$ Absorption Path Window .......... Length

Reference Thermocouples

Gas Inlet

\section{Purge Laser Gas Inlet}

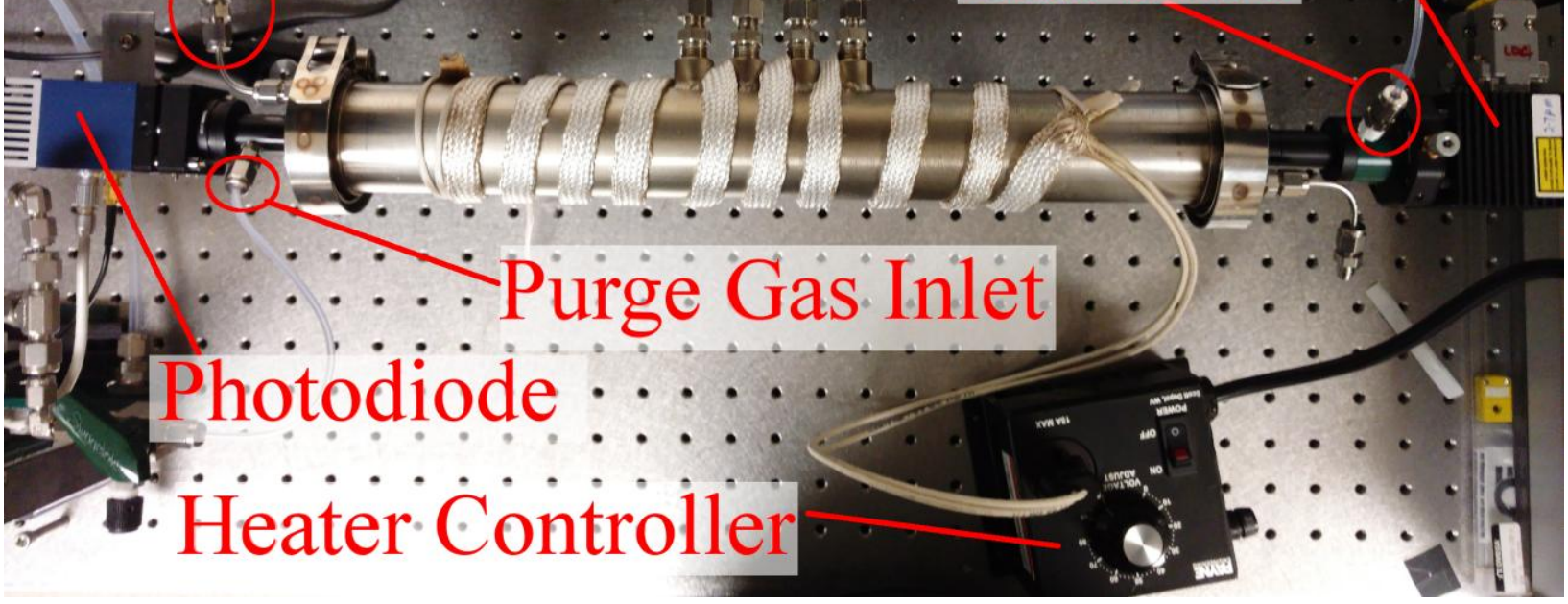




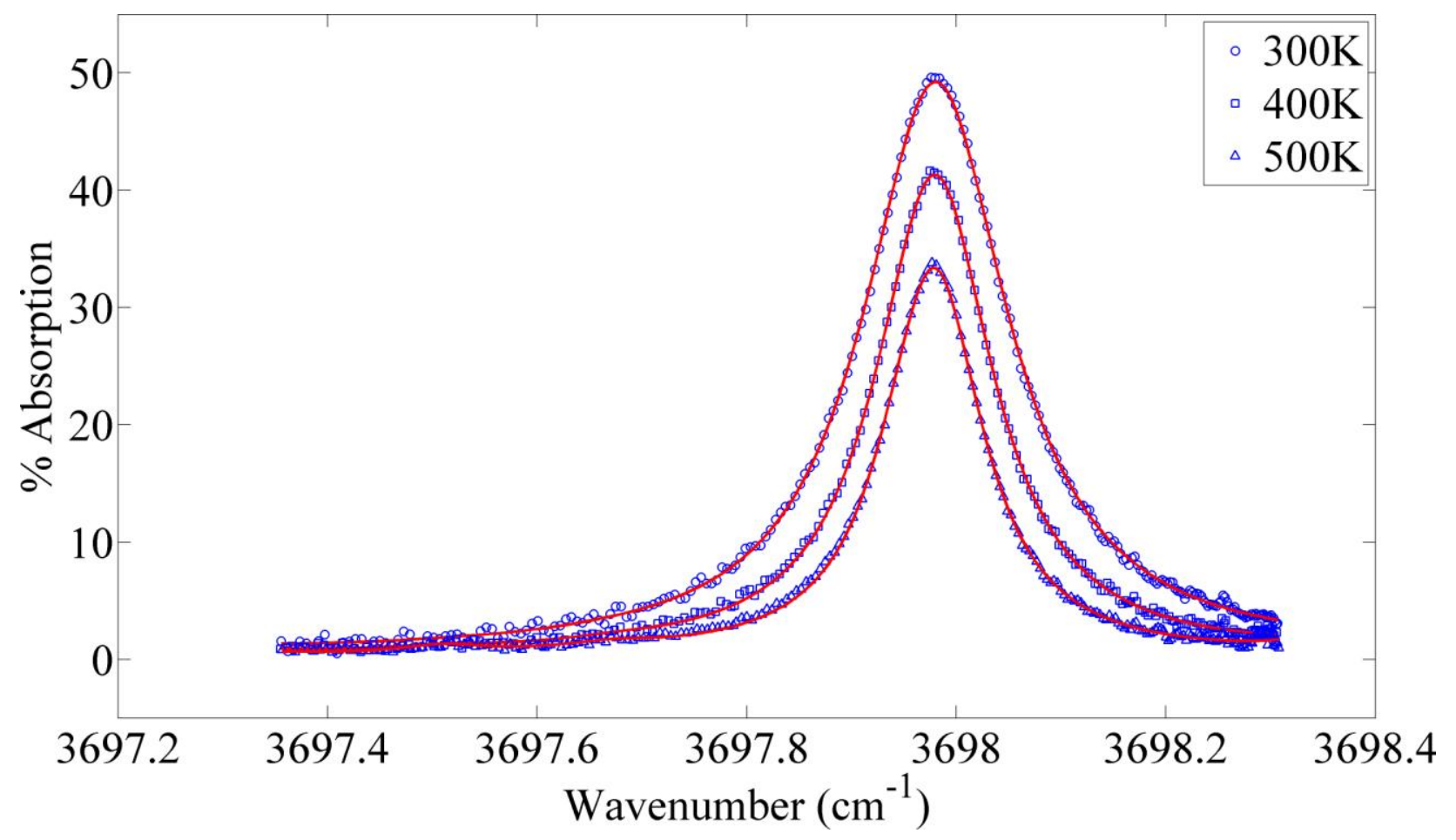




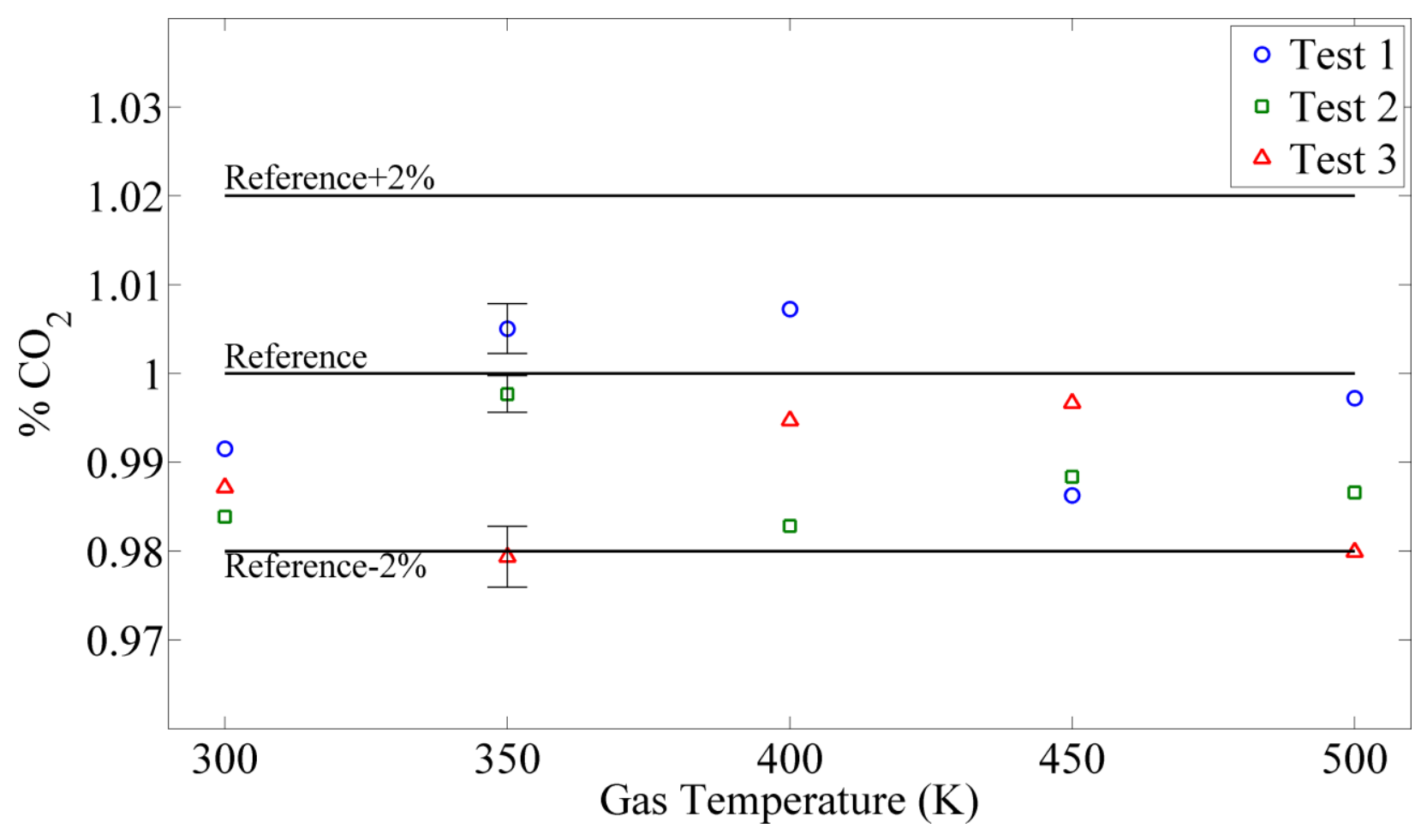




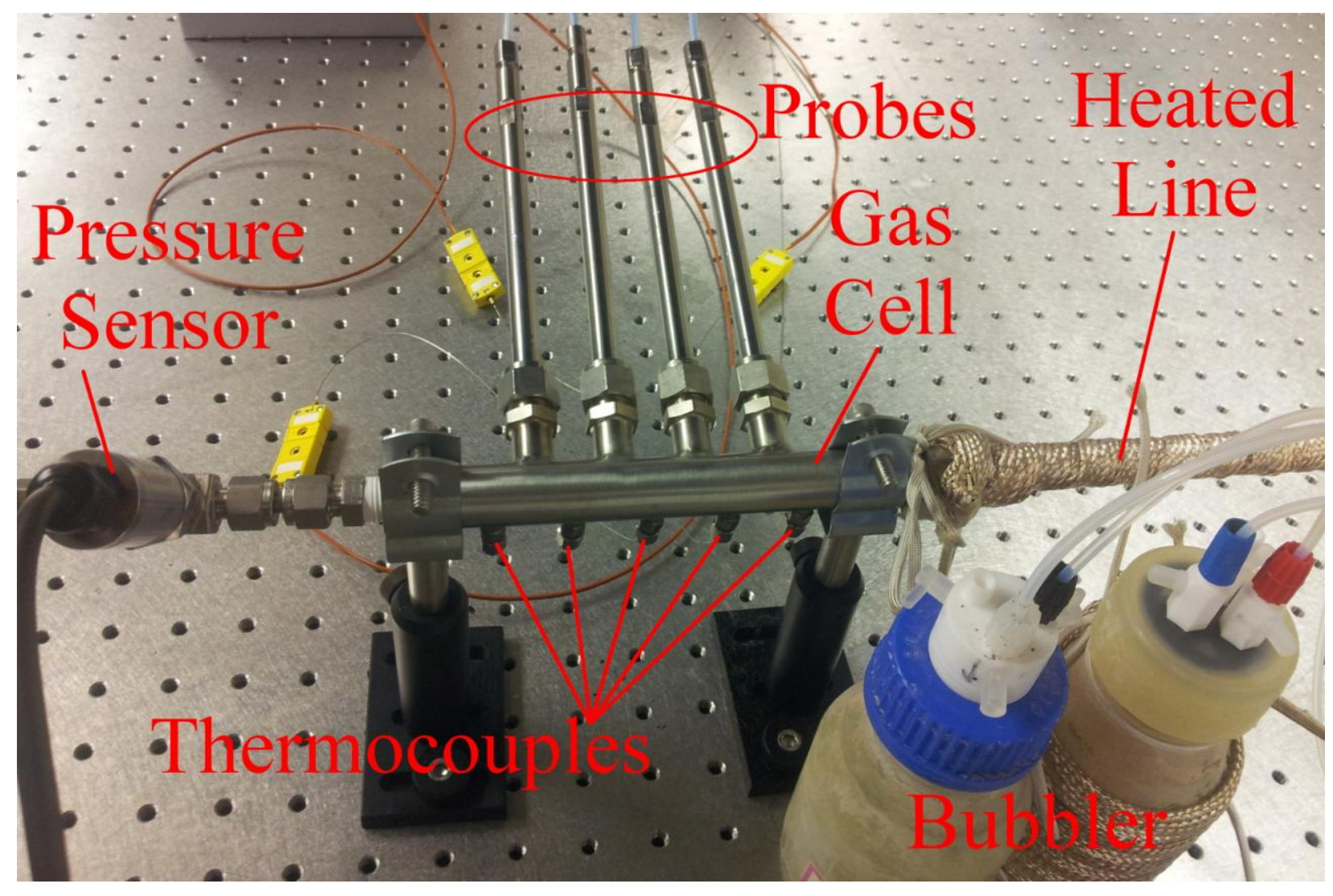




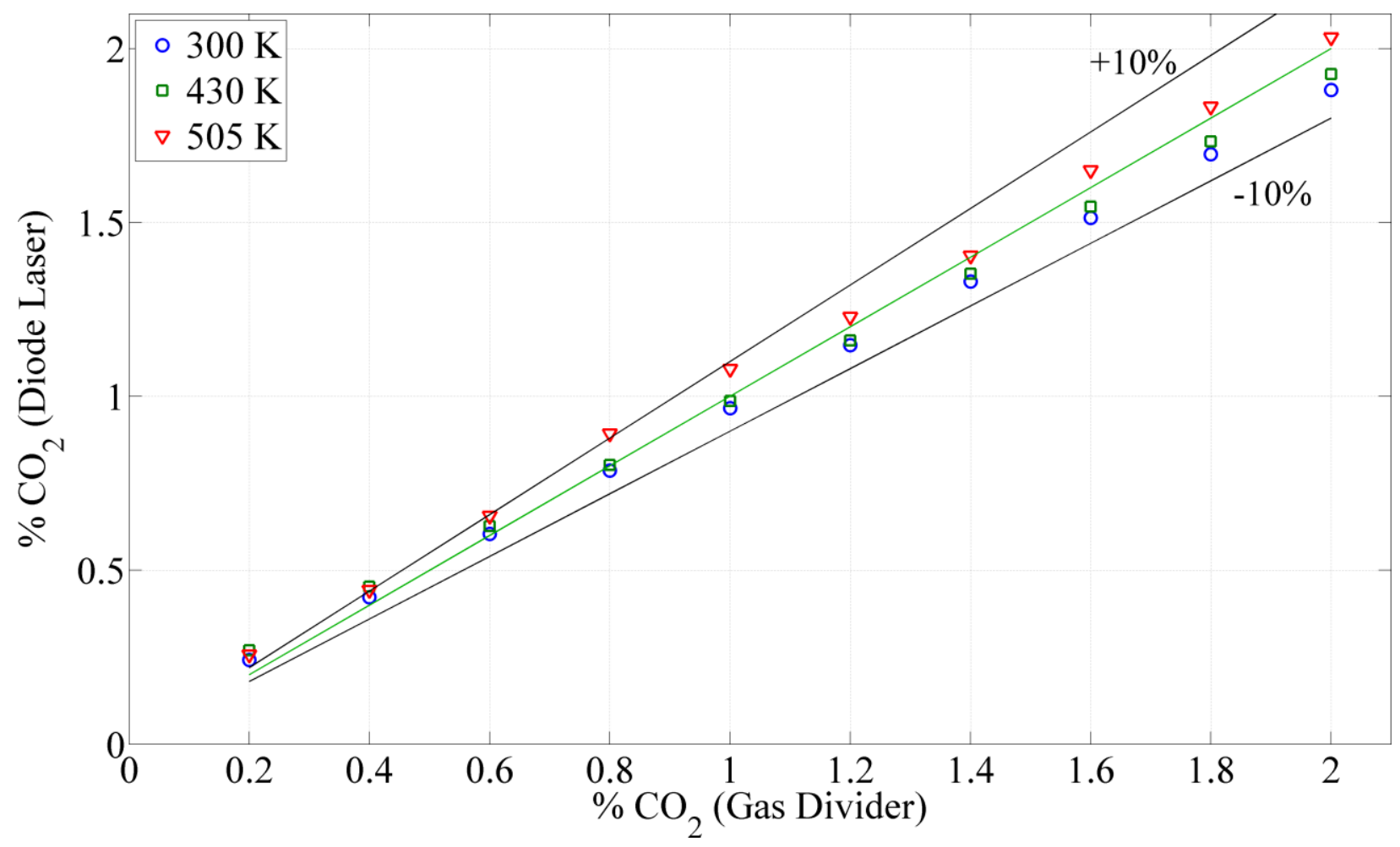




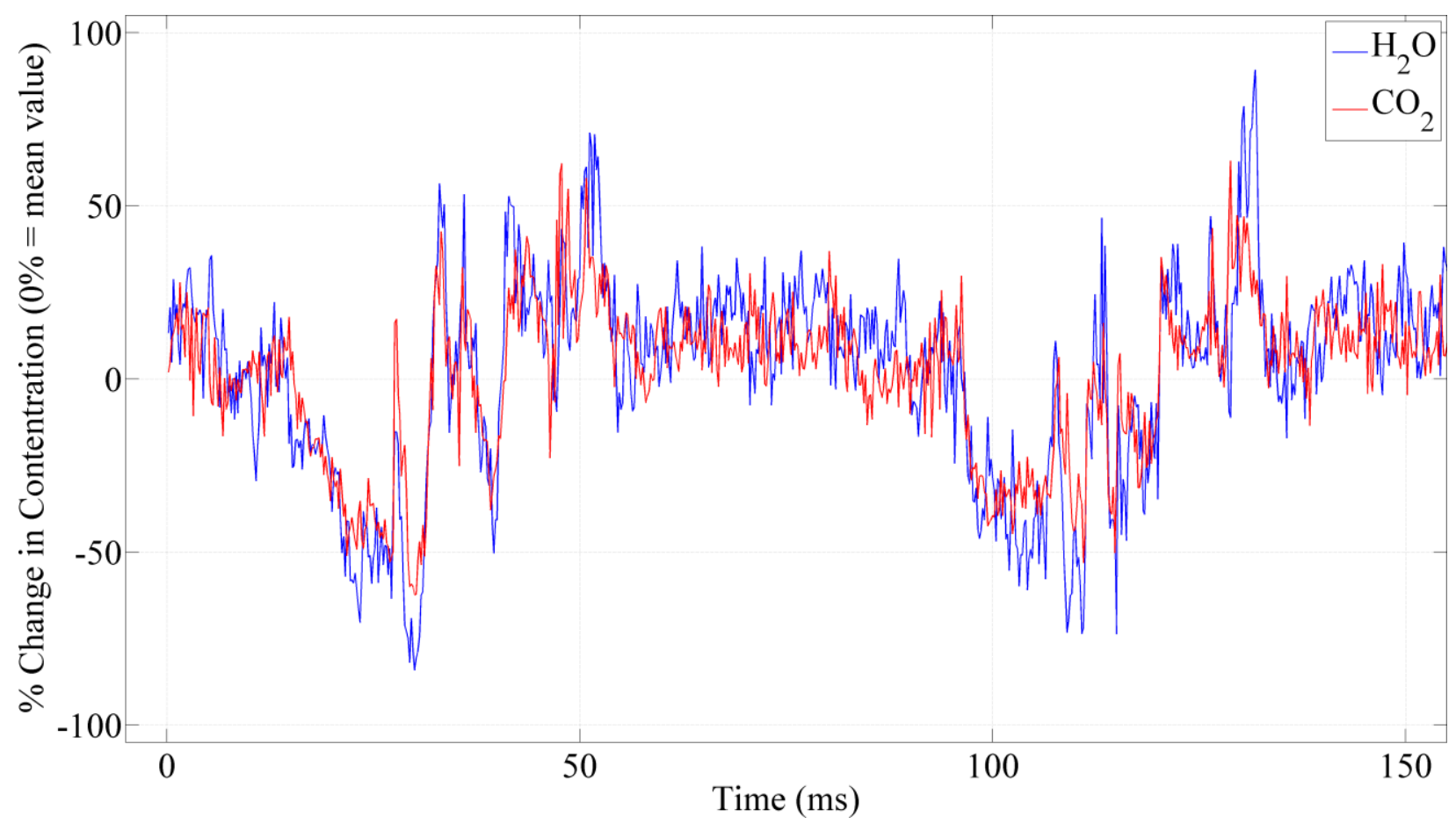

